\title{
DESENVOLVIMENTO DO SISTEMA ESTOMATOGNÁTICO DURANTE A VIDA INTRAUTERINA - REVISÃO DE LITERATURA
}

\section{DEVELOPMENT OF THE STOMATOGNATHIC SYSTEM DURING THE INTRAUTERINE LIFE - LITERATURE REVIEW}

\author{
Ítalo Cabral de Barros e SILVA ${ }^{1}$
}

italo_cbs@hotmail.com

Felipe Bandeira Cavalcanti De ANDRADE²

felipebandeira1994@gmail.com

Diego Belmiro do Nascimento SANTOS 3

diegobelmiro@outlook.com

Daniela Carvalho AZEVEDO ${ }^{4}$

dcazevedo07@gmail.com

Ana Carolina de Souza Leitão Arruda FALCÃO ${ }^{5}$

carolinafalcao@hotmail.com

\section{RESUMO}

Objetivo: Através de uma Revisão da Literatura, o trabalho busca consolidar informações sobre o desenvolvimento do sistema estomatognático, durante a vida intrauterina. Foram realizadas pesquisas sobre o tema abordado, nas seguintes bases de dados: Scielo, Medline; Bireme; Google Acadêmico e o PubMed, no intervalo de tempo de agosto de 2006 a junho de 2017. Livros publicados no mesmo período também foram consultados. Foram selecionados os artigos em português ou inglês, que contemplaram assuntos inerentes ao estudo. O desenvolvimento do sistema estomatognático acontece a partir do primeiro mês gestacional. A exposição materna a fatores de risco como infecções, traumatismos, desnutrição e consumo de drogas, pode deixar sequelas no feto, comprometendo estruturas e funções buco-dentais.

DESCRITORES: GRAVIDEZ; ODONTOGÊNESE; SISTEMA ESTOMATOGNÁTICO; DESENVOLVIMENTO EMBRIONÁRIO

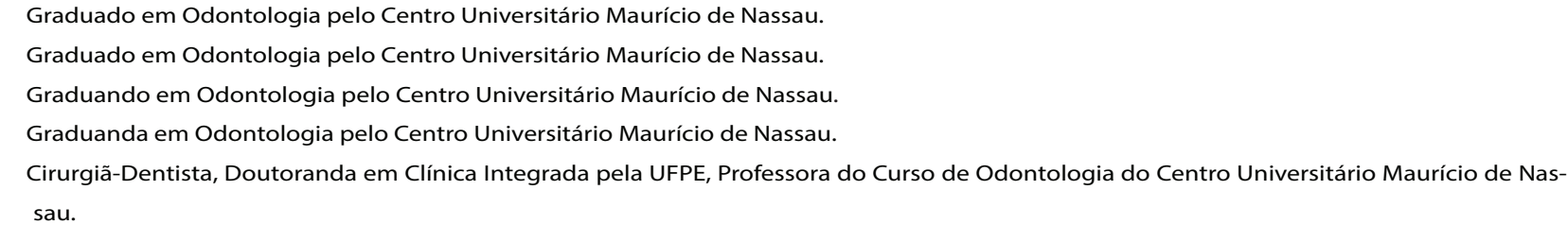


ISSN 1983-5183

\section{ABSTRACT}

Through a Literature Review, this work aims to consolidate information about the development of the stomatognathic system during the intrauterine life. The development of the stomatognathic system happens from the first gestational month. Maternal exposure to risk factors, such as infections, trauma, malnutrition, drug use, may leave sequels in the fetus and may compromise buccal-dental structures and functions.

DESCRIPTORS: PREGNANCY; ODONTOGENESIS; STOMATOGNATHIC SYSTEM; EMBRYONIC DEVELOPMENT

\section{INTRODUÇÃO}

Diferentes fases de crescimento e desenvolvimento dos órgãos do embrião podem ser observadas durante a gestação, o que permite a avaliação de várias condições de normalidade ou possíveis alterações, a cada etapa de formação intraútero'.

Quadros infecciosos, alterações hormonais e hematológicas, deficiências nutricionais, exposições a radiações, traumatismos, entre outras causas, podem gerar intercorrências na saúde materna e interferir sobre as condições de normalidade do feto. O conhecimento do desenvolvimento do sistema estomatognático desde o período embrionário torna possível uma melhor compreensão, quando as sequelas acometem a cavidade bucal do ser em formação, facilitando, assim, diagnósticos, prognósticos e planos de tratamentos ${ }^{1,}$ $2,3,4$.

Através de uma Revisão da Literatura, este estudo visa elucidar aspectos fisiológicos e possíveis interferências sobre a formação de estruturas dentárias, musculares e ósseas, durante os trimestres gestacionais; informações relevantes, de interesse multidisciplinar no atendimento infantil.

\section{GESTAÇÃO}

A gestação corresponde ao período de tempo necessário ao desenvolvimento do embrião no útero, que vai desde a fecundação até o nascimento. Terá início quando o gameta feminino for fecundado pelo gameta masculino De acordo com o Colégio Americano de Obstetrícia e Ginecologia, pode ser classificada em "a termo inicial"; "a termo"; "a termo tardio" e "pós-termo", a depender da quantidade de semanas que durar a condição. $O$ exame ultrassonográfico é o exame padrão ouro, a fim de indicar se há vida fetal e o seu correto desenvolvimento ${ }^{5,6}$.

Como regra, o período gestacional corresponde a 9 meses (três trimestres), quando inúmeros fenômenos fisiológicos acontecerão no ventre materno até o final do ciclo. A fecundação do óvulo pelo espermatozoide fará surgir o zigoto, que sofrerá inúmeras mitoses até originar o embrião. Esse processo de multiplicação celular é chamado de clivagem, dando origem aos blastômeros. Por volta da sétima semana ocorrerá a nidação, fixação do embrião na parede uterina. Após as sucessivas mitoses o embrião de 16 células será chamado de mórula. Com 32 células já será chamado de blastocisto ${ }^{1,5}$.

O saco vitelino irá surgir na sexta semana como um arcabouço esférico, revestido por inúmeros vasos pequenos que se juntam no alicerce do ducto vitelino para unir o saco vitelino à parte ventral do embrião com o intestino e a circulação sanguínea. Será responsável pelo aprovisionamento e transferência do vitelo para alimentar o embrião antes que o cordão umbilical ou placenta verdadeira estejam consolidados; e também pelo processo de hematopoese, caracterizado pela formação das primeiras células do sangue ${ }^{1,2,7}$. 
SILVA ÍCB, ANDRADE FBCD, SANTOS DBN, AZEVEDO DC, FALCÃO ACSLA. Desenvolvimento do sistema estomatognático durante a vida intrauterina - revisão de literatura. Rev. Odontol. Univ. Cid. São Paulo 2019 jan-mar; 31(1): 47-56

ISSN 1983-5183

A placenta é um órgão da relação materno-fetal de carácter temporário, responsável pela transferência de nutrientes e substâncias para o feto. Será responsável por intervir na inserção do embrião na parede uterina, criando um aparato biológico que torna possível a nutrição e troca de gases entre a genitora e o feto e desperta o perfilhamento gestacional, quando ocorrerá uma mudança do ciclo hormonal através da produção parácrina e endócrina. A membrana plasmática da barreira placentária será responsável por esse controle ${ }^{2,6}$.

Durante o período gestacional, através do fluxo sanguíneo, ocorre o transporte de substâncias da mãe para o feto. Apesar de existir uma barreira placentária, esta pode ser total ou parcial e, assim, drogas, vírus e bactérias podem conseguir ultrapassar, expondo o embrião a riscos ${ }^{1,2,3}$.

O álcool, o tabaco, entre outras drogas, se consumidas pela genitora, podem atravessar a placenta, sendo possível que o feto seja exposto às mesmas quantidades de substâncias químicas. O ser em formação apresenta o metabolismo mais lento e, assim, os produtos tóxicos ficam circulantes no líquido amniótico ${ }^{1,3}$.

Durante os trimestres gestacionais, as exposições supracitadas, assim como infecções maternas por microrganismos, podem gerar malformações (Tabela 01) ou mesmo o aborto do feto. A literatura cita 0 Treponema palidum, o Zika vírus, o citomegalovírus, entre outros, como possíveis agentes teratogênicos ${ }^{1,4}$.

A realização do exame de ultrassom no primeiro trimestre irá permitir examinar as condições de desenvolvimento, a possibilidade de certas anomalias. Com 18 semanas já será possível avaliar mais detalhadamente a anatomia fetal, sendo possível aferir o perímetro da cabeça, dando-nos condições de observar mais precisamente. A formação do Aparelho Faríngeo será o ponto de partida de todo esse processo de desenvolvimento, tem início entre a segunda e oitava semana da gestação ${ }^{8,9}$.

A gestação chega ao fim com o rompimento da bolsa, ocorrendo o extravazamento através do canal vaginal de líquido amniótico, a gestante entrará em trabalho de parto. Cerca de meia hora após o parto natural, a placenta será expulsa do últero, sendo o ciclo gestacional totalmente concluído',10.

\section{CRESCIMENTO E DESENVOLVIMENTO DO SISTEMA ESTOMATOGNÁTICO}

O Sistema Estomatognático é constituído por diversas estruturas, dentre elas articulações, ossos, músculos e dentes, que quando trabalham em conjunto irão participar de funções essenciais, como: a deglutição, a respiração, a fonação e a mastigação" ${ }^{911}$.

\section{MAXILARES}

O Aparelho Faríngeo começa a se desenvolver na segunda semana de gestação. A partir da terceira, é iniciado o processo de formação do estomodeu, que é a cavidade bucal primitiva. Os primórdios dos maxilares irão se originar do primeiro arco branquial, podendo serem observadas duas partes: a porção mandibular, que irá ser encarregada da formação da mandíbula e a porção maxilar, onde irão se formar os ossos maxilares, o arco zigomático e a porção escamosa do osso temporal9, 12, 13, 14.

Nessa fase, se a porção mandibular sofrer intercorrências, poderá resultar em malformações, como: a micrognatia, associada a pacientes como na Síndrome de Down (trissomia no cromossomo 21) ou mesmo assimetria mandibular, citada na Síndrome Goldenhar. Esta é caracterizada pela malformação dos primeiros e segundos arcos braquiais, sendo causada por fatores nutricionais e ambientais. Deficiências nutricionais, como insuficiência de cálcio, também poderão causar danos ao processo de osteogênese dos maxilares, 
SILVA ÍCB, ANDRADE FBCD, SANTOS DBN, AZEVEDO DC, FALCÃO ACSLA. Desenvolvimento do sistema estomatognático durante a vida intrauterina - revisão de literatura. Rev. Odontol. Univ. Cid. São Paulo 2019 jan-mar; 31(1): 47-56

ISSN 1983-5183

sendo mais susceptíveis às fraturas de mandíbula ${ }^{15,16}$.

A partir da quarta semana, poderemos observar o surgimento das fossas nasais e epitélio olfatório. 0 maxilar superior surgirá a partir da união das proeminências maxilares e frontonasal. A união dos processos maxilares laterais e nasal médio darão origem ao lábio superior. A fusão dos processos maxilares pode não ocorrer, de forma parcial ou total, resultando nas fendas palatinas, causadas às vezes por fatores genéticos, por exposição à radiação ionizante ou mesmo por fatores desconhecidos. Em condições normais, na sexta semana teremos já formado o palato primário, originando a pré-maxila, rebordo alveolar e parte interna do lábio superior ${ }^{12,14}$.

\section{ODONTOGÊNESE}

O processo de formação dos elementos dentários decíduos (primeira dentição) acontece a partir de interações entre o epitélio oral e o ectomesênquima, sendo chamado de odontogênese, que se inicia no final da sexta semana de vida intrauterina. A formação dos dentes permanentes inicia-se na $20^{\mathrm{a}}$ semana, a partir dos primeiros molares ${ }^{17}$. A exposição materna a drogas, fármacos, vírus e bactérias, além de carências nutricionais, poderão interferir no crescimento e desenvolvimento dos dentes ${ }^{3,5,6}$.

A amelogênese imperfeita é uma hipótese de alteração na estrutura dental e pode se apresentar de 3 formas: hipoplásica, quando a matriz do esmalte não está totalmente formada e este apresenta-se fino, origina-se a partir de uma deficiente formação da matriz orgânica; a hipocalcificada, em que a calcificação é deficitária, resultando em um esmalte frágil; e a hipomaturada, em que o cristal do esmalte apresenta defeitos na sua maturação, a coloração apresenta variações entre opaco, branco, marrom e amarelo. A dentina também pode ser acometida, quando ocorre a dentinogênese imperfeita. Os elementos dentários apresentam uma opalescência ou translucidez anormal, variando sua tonalidade de um cinza à violeta acastanhado, ou castanho amarelado. A amelogênese e a dentinogênese imperfeitas apresentam como fator de risco a hereditariedade ${ }^{18}$.

Modificações na cronologia de erupção dentária também podem ser diagnosticadas: crianças nascidas pré-termo (com menos de 37 semanas), abaixo do peso, com atraso na sequência eruptiva; além de pacientes sindrômicos, que podem apresentar de 6 a 18 meses de atraso, com relação à idade dental adequada à sua faixa etária15.

Entre as alterações de número dos dentes, pode-se observar as agenesias (ausência congênita de dentes), que surgem a partir de problemas no estágio de iniciação e proliferação do órgão dental. As diferenças na quantidade de elementos podem se apresentar, como: a hipodontia, quando o paciente tem no máximo 6 dentes faltando; a oligodontia, quando ultrapassa a barreira dos 6 dentes ausentes; e a anodontia, quando todos os dentes estão ausentes da cavidade oral. A maioria dos casos tem base genética, tendo ligação a mais de 120 tipos de Síndromes, como na Displasia Ectodérmica (Síndrome que afeta os tecidos derivados do ectoderma), na Síndrome de Rieger (doença autossômica dominante, displásica, com alterações oculares, dentárias e umbilicais) e na Síndrome de Down. Outras hipóteses podem estar associadas a traumas, ao efeito teratogênico de fármacos ou exposição à radiação, durante a gestação, casos que também podem apresentar fissuras lábio-palatinas, como sequelas ${ }^{17,19,20}$.

A dentição decídua corresponde a 20 dentes e a dentição permanente, a 32. Alterações na odontogênese também podem aumentar esse número, como no caso dos dentes supranumerários, associados a uma atividade excessiva da lâmina dentária, de etiologia pouco esclarecida ${ }^{17,20}$. 
SILVA ÍCB, ANDRADE FBCD, SANTOS DBN, AZEVEDO DC, FALCÃO ACSLA. Desenvolvimento do sistema estomatognático durante a vida intrauterina - revisão de literatura. Rev. Odontol. Univ. Cid. São Paulo 2019 jan-mar; 31(1): 47-56

ISSN 1983-5183

Os dentes ainda podem sofrer alterações de forma, como: a taurodontia, que tem origem a partir da invaginação retardada das células da Bainha epitelial de Hertwig, o que origina uma câmara pulpar mais longa que o normal. Ela geralmente está associada à displasia ectodérmica ${ }^{20}$. A fusão acontece quando dois germes em formação tentam se unir, resultando assim em um único elemento dentário maior que o normal. A geminação, outra anormalidade estrutural, acontece quando se tenta formar dois elementos, a partir de um único órgão dental, causando o surgimento de um dente com duas coroas distintas, mas que compartilham do mesmo conduto radicular. A etiologia da fusão e geminação é desconhecida, porém traumas, fatores ambientais, síndromes, além da hereditariedade, são possíveis fatores relacionados ${ }^{17}$. A literatura ainda cita os dentes de Hutchinson, que acometem incisivos, que se apresentam espaçados e com um entalhe central e molares, que se desenvolvem no formato de uma amora, associados a sequelas da sífilis congênita ${ }^{21}$.

\section{LÍNGUA}

A língua terá seu desenvolvimento iniciado ao final da quarta semana de vida intrauterina. Ela surge do mesênquima do primeiro par do arco faríngeo, como uma saliência lingual mediana, que se localiza no assoalho da faringe primata. Ao meio da quinta semana de desenvolvimento embrionário, surgem duas proeminências linguais laterais que se desenvolvem sobre a mediana e posteriormente se unem. $\mathrm{O}$ forte crescimento das saliências linguais laterais irá originar os dois terços anteriores da língua, já o terço posterior será originado a partir de duas novas saliências, que se formarão: a cópula e a saliência hipofaríngea9, 22.

Uma das principais anomalias de desenvolvimento que podem acometer a língua é a macroglossia verdadeira, relacionada a síndromes congênitas, como as Síndromes de Beckwhith-Wiedemann (Síndrome decorrente de uma alteração no braço curto do cromossomo 11.) e Hurler (Síndrome originada da deficiência genética de enzimas lisossômicas, que irão fazer a hidrólise de mucopolissacarídeos) que pode trazer sérios problemas respiratórios, de deglutição, de fonação e também interferir na estética ${ }^{23}$. A microglossia é mais rara, apresenta-se como uma língua primitiva, diminuída em relação ao tamanho. É causada por trauma na célula fetal no princípio da gestação ${ }^{24}$.

A aglossia, caso grave, corresponde a ausência congênita da língua. Apresenta-se como uma falha da embriologia da língua, que acontece entre quarta e oitava semanas de gestação. Ela apresenta associação com algumas síndromes congênitas, como as Síndromes de Pierre Robin (Síndrome congênita originada a partir dos $1^{\circ}$ e $2^{\circ}$ arcos faríngeos) e Moëbius (decorrente da formação anormal dos nervos cranianos) ${ }^{25}$. Observam-se, ainda, os casos de anquiloglossia, uma alteração no desenvolvimento da língua que tem como característica a baixa inserção do freio lingual, restringindo assim seus movimentos, com etiologia pouco esclarecida ${ }^{26}$.

\section{LÁBIO}

O ponto inicial da formação dos lábios se dá quando os processos nasal médio e maxilares laterais irão dar origem ao lábio superior, isso ocorre por volta da sexta semana de vida intrauterina. Uma alteração que pode ser vista no lábio é a fissura labial, quando os processos maxilares e nasal medial não estiverem unidos. A etiologia das fissuras é multifatorial, a hereditariedade é dada como uma das principais causas, porém, pode também ter origem em fatores ambientais como: ingestão de drogas no primeiro trimestre de gestação, como anticonvulsivantes; tabagismo; exposição à radiação ionizante e deficiências nutricionais ${ }^{15,27}$. 


\section{ARTICULAÇÃO TEMPOROMANDIBULAR}

Articulação Temporomandibular (ATM) tem seu desenvolvimento a partir de blastemas que iniciam sua formação de forma distinta. Por volta da $10^{\text {a }}$ semana de vida intrauterina, o crescimento do blastema condilar que dará origem ao côndilo, aproxima-se do blastema temporal que irá originar a fossa glenoide e a eminência articular do temporal. $O$ disco articular surgirá por volta da $10^{\text {a }}$ semana e a cápsula articular por volta da $11^{\text {a }}$ semana. Na $12^{\text {a }}$ semana de vida intrauterina, a ATM do feto já irá apresentar forma e composição bem definidas. Após esse período, ela só irá aumentar de tamanho, seguindo o crescimento que o feto terá como um todo9, 11 .

Várias Síndromes podem ter como características alterações na ATM. Pacientes acometidos pela Trissomia do cromossomo 21 sofrem, por conta da menor tonicidade, de uma maior flexibilidade e laxidez ligamentar ${ }^{16}$. A agenesia ou hipoplasia condilar pode trazer sérias complicações para o portador, como, por exemplo uma diminuição na mobilidade mandibular e também uma abertura de apenas alguns milímetros da boca. Essa condição pode ser encontrada na Síndrome Aurículo-condilar (doença autossômica dominante que atinge os dois primeiros arcos faríngeos, apresentando alterações auriculares, na mandíbula e ATM) ${ }^{28}$. A Microssomia Hemifacial afeta os dois primeiros arcos faríngeos e causa alterações no osso temporal, na cabeça da mandíbula e, em casos mais severos, pode causar fissura orbital ou até agenesia do côndilo mandibular. Essa anomalia congênita tem como característica a redução do corpo da mandíbula, causando desvio do mento para o lado abalado ${ }^{29}$.

\section{MÚSCULOS}

Os músculos da mastigação (temporal, masseter, pterigoideo lateral e medial) e da expressão facial (bucinador, frontal, platisma, orbicular dos lábios e orbicular dos olhos) se originam do primeiro e segundo arcos faríngeos, que começam seu desenvolvimento por volta da $4^{\text {a }}$ semana de vida intrauterina, e do terceiro arco faríngeo que serão responsáveis pela formação do músculo estilofaríngeo. A partir do quarto arco, originam-se os músculos situados nas regiões da úvula, palato, faringe e tireoide ${ }^{30}$.

Os movimentos decorrentes da deglutição começarão a acontecer por volta da décima segunda semana de gestação. Seus movimentos terão a função de levar o bolo alimentar até o estômago e isso acontece através de seguidas contrações musculares. A formação dos músculos vai permitir que a partir da décima terceira semana de gestação a sucção já possa ser notada, porém ela só terá uma resposta mais localizada e aprimorada por volta da $29^{a}$ semana e será totalmente especializada na $32^{\mathrm{a}}$ semana de gestação $0^{5,14}$.

Por volta da vigésima sexta semana teremos toda a estrutura craniofacial já formada. Desse período em diante o sistema estomatognático irá desenvolver-se não mais por formação de novas estruturas, mas sim pelo crescimento espontâneo que vai garantir o correto funcionamento de suas funções vitais. Depois do nascimento do ser humano, acontecerá desenvolvimento da fala e da mastigação ${ }^{14}$. 
SILVA ÍCB, ANDRADE FBCD, SANTOS DBN, AZEVEDO DC, FALCÃO ACSLA. Desenvolvimento do sistema estomatognático durante a vida intrauterina - revisão de literatura. Rev. Odontol. Univ. Cid. São Paulo 2019 jan-mar; 31(1): 47-56

ISSN 1983-5183

Tabela 1. Desenvolvimento do Sistema Estomatognático durante a vida intrauterina e as possíveis sequelas no feto, diante de intercorrências maternas.

\begin{tabular}{|c|c|c|c|}
\hline Estrutura & $\begin{array}{l}\text { Início do desenvol- } \\
\text { vimento intraute- } \\
\text { rino }\end{array}$ & Fatores de risco & Alterações \\
\hline Mandíbula & $3^{a}$ semana & $\begin{array}{l}\text { deficiências nutricionais; } \\
\text { síndromes; fatores genéti- } \\
\text { cos; radiações ionizantes; } \\
\text { infecções; traumatismos; }\end{array}$ & $\begin{array}{l}\text { micrognatia; assimetrias; } \\
\text { hipocalcificação }\end{array}$ \\
\hline Maxila & $3^{\text {a }}$ semana & Tahagismo. uso de drogas & fenda palatina \\
\hline Língua & $4^{\mathrm{a}}$ semana & & $\begin{array}{c}\text { macroglossia; microglossia; } \\
\text { aglossia; anquiloglossia }\end{array}$ \\
\hline Odontogênese & $6^{\mathrm{a}}$ semana & & $\begin{array}{l}\text { alterações de número, for- } \\
\text { ma e estrutura dentárias }\end{array}$ \\
\hline Lábios & $6^{\mathrm{a}}$ semana & & Fissura labial \\
\hline ATM & $8^{\mathrm{a}}$ semana & & $\begin{array}{l}\text { Hipotonicidade; hipoplasia } \\
\text { condilar }\end{array}$ \\
\hline
\end{tabular}

\section{DISCUSSÃO}

A saúde materna e a do ser em formação devem ser monitoradas durante toda a gestação, o que pode prevenir doenças, identificar malformações, alterações no crescimento e desenvolvimento do feto, facilitando, assim, diagnósticos; prognósticos e até intervenções médicas precoces, a fim de proteger vidas ${ }^{6,8}$.

A placenta, através do seu gradiente de concentração, permite selecionar substâncias que são levadas para o feto e, assim, funciona como barreira natural. No entanto, inúmeros agentes patogênicos, efeitos teratogênicos de drogas, radiações, entre outros agentes, podem ultrapassar a barreira natural e resultar em danos ao feto, interferindo no correto desenvolvimento das estruturas orgânicas ${ }^{1,2,3}$.

A ultrassonografia representa um exame "padrão ouro" para o acompanhamento da vida intrauterina ${ }^{6,8}$ e o primeiro trimestre gestacional representa um período que requer maior atenção, quando ocorre a organogênese, período em que os folhetos embrionários sofrem diferenciação e originam os órgãos, incluindo os do sistema estomatognático ${ }^{14}$.

De acordo com a literatura, alterações no crescimento e desenvolvimento das estruturas do sistema estomatognático nem sempre poderão ser identificadas através do exame ultrassonográfico. No entanto, o acompanhamento do perímetro cefálico, a princípio, a partir da décima oitava semana, pode sinalizar para o adequado desenvolvimento do estomodeu, que tem início de formação desde a terceira semana

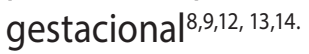

Ao final do segundo trimestre e o início do terceiro, será possível a análise morfológica e anatômica dos maxilares, sendo possível precisar a relação harmônica intermaxilares. Casos de micrognatia, por exemplo, poderão ser identificados de forma precoce, permitindo o monitoramento de possíveis repercussões ao bebê. Em outras hipóteses, como fendas palatinas, no entanto, o diagnóstico mais preciso acontece apenas após o nascimento, quando o tratamento é planejado ${ }^{8,12,14}$. Nesses casos, com ou sem 
SILVA ÍCB, ANDRADE FBCD, SANTOS DBN, AZEVEDO DC, FALCÃO ACSLA. Desenvolvimento do sistema estomatognático durante a vida intrauterina - revisão de literatura. Rev. Odontol. Univ. Cid. São Paulo 2019 jan-mar; 31(1): 47-56

ISSN 1983-5183

envolvimento de fenda labial, pode ser realizada pouco depois do nascimento a abordagem cirúrgica (zetaplastia), plástica e reparadora, permitindo melhor qualidade de vida para a criança, corroborando, inclusive, a sucção durante a amamentação ${ }^{12,14}$. Na macroglossia, geralmente apenas com o exame clínico da criança é possível a identificação da alteração. O planejamento cirúrgico pode ser indicado e removido o tecido excedente. Casos de microglossia e aglossia são mais raros e de tratamento muito mais complexo, requerendo acompanhamento multidisciplinar. Casos de anquiloglossia podem ser diagnosticados logo após o parto, através de exames anotomofuncionais, com o Teste da Linguinha, e o tratamento pode ser cirúrgico (frenotomia, frenectomia ou frenuloplastia) ou conservador, o que deve ser avaliado pela equipe multidisciplinar, formada por médicos, dentistas e fonoaudiólogos ${ }^{12,24}$.

Evidencia-se que há uma impossibilidade de realizar o diagnóstico das anomalias dentárias ainda na fase intrauterina com os métodos de diagnósticos atuais, pois, o acompanhamento só é possível após o nascimento, por meio de radiografias e exame clínico ${ }^{17,18}$. Algumas síndromes, no entanto, diagnosticadas através de exames de imagem, a Síndrome de Down, ou outras alterações, como a Displasia Ectodérmica ou o diagnóstico da Sífilis congênita, já podem sugerir a presença das anomalias dentárias no feto ${ }^{17,18}$.

Quando as alterações de número, forma ou estrutura são encontradas, podem comprometer a estética e a função mastigatória e, assim, oportunamente, de acordo com o caso a caso, procedimentos preventivos, restauradores, cirúrgicos, protéticos, ortodônticos podem ser indicados ${ }^{17,18,20}$.

Alterações no feto ainda podem acometer o desenvolvimento muscular e a ATM, o que futuramente pode comprometer a qualidade de vida do indivíduo, com quadros dolorosos, além de limitações nos movimentos mandibulares. Durante a vida intrauterina, podem ser diagnosticadas a Síndrome de Down, a

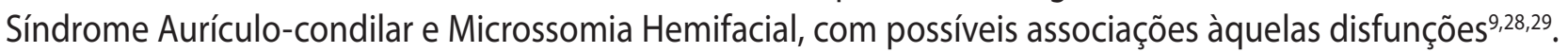

A agenesia condilar tem forte ligação com a Síndrome Aurículo-condilar e a Microssomia Hemifacial, geralmente com indicação de tratamentos ortopédicos, cirúrgicos e até ortodônticos, associados ${ }^{28,29}$.

\section{CONCLUSÃO}

O acompanhamento do desenvolvimento da vida intrauterina é essencial no diagnóstico precoce de riscos e possíveis alterações às estruturas do organismo fetal. A avaliação ultrassonográfica, nesse período, no entanto, encontra limitações no exame do sistema estomatognático, o que não impede de indicar imagens sugestivas de malformações musculoesqueléticas, bem como o diagnóstico de síndromes, que, assim como a presença de infecções maternas durante a gestação, podem representar sequelas de interesse buco-dental.

\section{REFERÊNCIAS}

1. MONTANARI T. Embriologia: texto, atlas e roteiro de aulas práticas. Porto Alegre: Edição do autor; 2013.

2. BROLIO MP, Ambrósio CE, Franciolli AR, Morini AC, Guerra RR, Miglino MA. A barreira placentária e sua função de transferência nutricional. Rev Bras Reprodução Animal 2010 34(4):222-32.

3. YAMAGUCHI ET, Cardoso MMSC, Torres MLA, Andrade AG. Drogas de abuso e gravidez. Rev psiquiatr clín 2008 35(Suppl 1):44-7. 
ISSN 1983-5183

4. ADIBI JJ, Marques ET, Jr., Cartus A, Beigi RH. Teratogenic effects of the Zika virus and the role of the placenta. Lancet (London, England) 2016 Apr 9;387(10027):1587-90.

5. SILVA CO, Furtado J, Sales MG, Rafalski NF. A gravidez na adolescência. Rev Universo Enfermagem 2014 3(2):79-82.

6. ACOG Committee Opinion No 579: Definition of term pregnancy. Obstetrics and gynecology 2013 Nov;122(5):1139-40.

7. GALDOS-RIVEROS AC, Rezende LC, Pessolato AGT, Miglino MA. A relação biológica entre o saco vitelino e o embrião. Rev Enciclopédia Biosfera 2010 6(11):1-13.

8. ACOG Practice Bulletin No. 101: Ultrasonography in pregnancy. Obstetrics and gynecology 2009 Feb;113(2 Pt 1):451-61.

9. CAMPOS B, Susanibar F, Carranza CA, Oliveira NCM. Embriologia do sistema estomatognático. In: Susanibar, F, Marchesan, IQ, Ferreira, VEJA, Douglas, CR, Parra, D, Dioses, A. Motricidade orofacial: fundamentos desenvolvimento do SE durante a vida intrauterina neuroanatômicos, fisiológicos e linguísticos. Ribeirão Preto: Book toy; 2015. p. 23-60.

10. SILVA SL, Marques IR. Análise de registro de dados obstétricos em prontuários. Cogitare enferm 2007 abr.-jun. ;12(2):150-6.

11. PEREIRA N. Desenvolvimento da ATM e prevalência de desordens temporomandibulares em crianças (Revisão Bibliográfica) [Dissertação]. Porto: Universidade Fernando Pessoa, Faculdade de Ciências da Saúde; 2011.

12. NEVILLE BW, Damm DD, Allen CM, Bouquot JE. Patologia Oral \& Maxilofacial. 3. ed. Rio de Janeiro: Elsevier; 2009.

13. TEIXEIRA PJS. Protocolo de avaliação orofacial: um contributo para a sua revisão e validação [Dissertação]. Lisboa: Escola Superior de saúde do Alcoitão, Santa Casa da misericórdia de Lisboa; 2015.

14. MELO EMC. Fissuras labiopalatinas: alterações morfofuncionais e avaliação do tratamento [Dissertação]. Recife, PE: Universidade Federal de Pernambuco; 2007.

15. MACHO VMP, Seabra M, Pinto A, Soares D, Andrade C. Alterações craniofaciais e particularidades orais na trissomia 21. Rev Acta Pediatr Port 2008 39(5):190-4.

16. BUSANELLO AR, Silva AMT, Christmann MK, Finamor MM, Sonego MT, Barcellos RA, et al. Síndrome de Goldenhar: uma abordagem fonoaudiológica. Rev CEFAC 2012 14(3):566-73.

17. URIO EK. Prevalência de anomalias dentárias em dentição decídua de pré-escolares atendidos na escola do Sesc Dourados/MS [Dissertação]. Brasília: Universidade de Brasília; 2007.

18. PASSOS IA, Costa JDMC, Melo JM, Forte FDS, Sampaio FC. Defeitos do esmalte: etiologia, características clínicas e diagnóstico diferencial. Rev Inst Ciênc Saúde 2007 25(2):187-92. 
ISSN 1983-5183

19. DINIZ MB, Coldebella CR, Zuanon ACC, Cordeiro RCL. Alterações orais em crianças prematuras e de baixo peso ao nascer: a importância da relação entre pediatras e odontopediatras. Rev paul pediatr 2011 29(3):440-53.

20. GOMES RR. Manifestações bucais em indivíduos com Oligodontia e seus familiares do Hospital Universitário de Brasília [Dissertação]. Brasília Universidade de Brasília; 2008.

21. GUIDI R. Manifestações bucais da sífilis: estudo retrospectivo [Dissertação]. Uberlândia, MG Universidade Federal de Uberlândia; 2007.

22. ANDREZZO M. Desenvolvimento da língua e sua relação com deglutição e sucção pré-natais [Trabalho de Conclusão de Curso de Graduação]. Florianópolis, SC: Universidade Federal de Santa Catarina; 2014.

23. KAISER JM, Collares MVM, Pinto RA, Oliveira ACP, Portinho CP, Viaro MS. Tratamento cirúrgico de macroglossia na síndrome de beckwith-wiedemann: relato de caso ACM arq catarin med 2007 jun.;36(supl.1):138-9.

24. NEPRAM S, Jain P, Huidrom R. Isolated microglossia: a case report. J Medical Society 2015 set.;29(3):180-1.

25. BOMMARITO S, Zanato LE, Vieira MM, Angelieri F. Aglossia: case report. Int Arch Otorhinolaryngol 2016 20(1):87-92.

26. MELO NSFO, Lima AAS, Fernandes Â, Silva RPGVC. Anquiloglossia: relato de caso. RSBO 2011 Jan-Mar;8(1):102-7.

27. FERNANDES R, Defani MA. Importância da equipe multidisciplinar no tratamento e proservação de fissuras labiopalatinas. Rev Saúde Pesquisa 2013 6(1):109-16.

28. TAVARES VLR. Identificação de mutações associadas à síndrome Aurículo-Condilar [Dissertação]. São Paulo Universidade de São 2011.

29. RIBEIRO FAV, Toledo B, Santamaria Junior M, Vedovello SAS, Valdrighi HC. Tratamento não cirúrgico de microssomia hemifacial por meio da ortopedia funcional dos maxilares. Rev Gaúch Odontol 2011 59(1):131-4.

30. PITTOLI SVP. Investigação radiológica e tomográfica da mandíbula de indivíduos com anomalias de $1^{\circ}$ e $2^{\circ}$ arcos faríngeos (2011) [Tese]. Bauru: Universidade de São Paulo; 2011.

RECEBIDO EM 24/09/2018

ACEITO EM 21/01/2019 